\title{
Friends of the Earth International: Negotiating a Transnational Identity ${ }^{1}$
}

\author{
Brian Doherty ${ }^{1}$
}

This is an electronic version of an article published in Environmental Politics Volume 15, Issue 5, 2006, pp.860-880.

Special Issue: Beyond Borders: Environmental Movements and Transnational Politics. Environmental Politics is available online at: http://www.tandfonline.com/doi/abs/10.1080/09644010600937306

\begin{abstract}
The aim of this article is to assess the relationships between majority (South) and minority (North) world environmental groups by focussing on one of the largest transnational environmental organisations: Friends of the Earth International (FoEI): ${ }^{2}$ a federation of autonomous groups from 71 countries (see Appendix). FoEI's federal structure gives more power to Southern groups than other transnational environmental organisations and FoEI has taken a relatively radical line on issues of global justice. Nevertheless there have been arguments over strategy and ideology between Northern and Southern groups. The article examines how FoEI responded to a crisis in its identity over NorthSouth differences in 2002-4. The trust developed through regular international meetings and a distinctive organisational culture allowed the network to rebuild its solidarity, though without ever fully resolving differences of ideology. It is argued that FoEI will be best able to maintain its North-South representation if it accepts that internal conflicts and debates over core ideological questions are normal for social movements.
\end{abstract}

There are many reasons for seeing transnational action as increasing in importance for the environmental movement, but among the least understood are the processes by which actors from different countries develop collective identities capable of jointly defining injustice and mobilising action across national borders (Tarrow and della Porta 2005: 228-9). This is arguably more of a challenge for the environmental movement than for many others. Whereas movements based on gender, sexuality, ethnicity and religion can draw upon their common characteristics to define their solidarity across national borders (Rupp and Taylor 1999), environmentalists must evoke a universal humanity (Smith 2002). This is also a feature shared with human rights and development social movement organisations, but when it comes to developing a common agenda divisions have emerged

${ }^{1}$ Correspondence address: Brian Doherty, School of Politics, International Relations and Philosophy Keele University, ST5 5BG, United Kingdom. Email: b.j.a.doherty@keele.ac.uk 
in many of these kinds of trans-national groups between those from the global South and those from the global North. Southern human rights groups have argued that human rights require action on economic and social inequality before civil and political rights can be made meaningful. They have accused Northern groups of failing to expand their understanding of human rights to give due attention to the structural causes of abuses of human rights (Steiner 1991, in Smith 2002: 508). Development coalitions such as Jubilee 2000 have split on North-South grounds (Anheier and Themudo 2002: 189) and there is a common pattern of Southern critiques of Northern NGOs as acting in ways that maintain the dependency of Southern NGOs (Princen and Finger 1994; Edwards and Gaventa 2000; Bob 2001). The expansion of democracy and international regimes on human rights and the environment has increased the space for NGO and wider social movement activity in many Southern countries, but democracy remains weak in many countries, and non-existent in others, with repression and violence a threat to many social movements. Northern NGOs are operating in safer political contexts and as their governments are usually more powerful actors on the international stage it is common for Southern social movements to see Northern partners as too close to their own governments.

These differences pose a major obstacle to efforts to develop trans-national collective identities and common action. Added to this are the much greater resources of most Northern organisations, including the environmental movements. This has led some to argue that a global environmental movement is still a long way off (Rootes 2004) And yet, as transnational collective action is increasing in frequency (Anheier et al. 2005), we might expect that increased interaction will lead to dialogue and common learning. Smith's (2002) research on affiliates to EarthAction, a support network providing campaign materials for independent environmental groups worldwide, two thirds of whose affiliates are in the South, found that there was a strong shared commitment to global solidarity across the NorthSouth divide. It was on strategy that differences began to emerge, with scepticism from some Southern groups about the stress of EarthAction on strengthening the UN, when the UN structure remained so undemocratic and dominated by Northern governments. As Smith notes, 'Transnational groups have been fairly readily able to generate shared views of the problems they address, but they appear to face far greater challenges in articulating common responses to these problems.' (2002: 521). This suggests that dealing successfully with the problem of strategy is essential to the ability of environmental movements to play an effective role in transnational politics.

FoEI's federal structure makes it distinct from the two other largest international environmental NGOs: Greenpeace and the World Wide Fund for Nature (WWF). Greenpeace is a centralised organisation with franchises in 38 different states $^{3}$ but under the control of its International Office, 
which, in turn, is directed by a board constituted according to the level of finance provided by national franchises. This means that the Dutch, German, UK, US and Australian branches control the majority of posts (Kellow 2000). In contrast, in FoEI each of the 71 national groups has an equal vote irrespective of the size of its membership or financial contribution to the Federation. As the FoEI network has expanded it has been increasingly driven by the major concerns of its Southern members, despite the wealthiest and largest groups being from Northern countries. More than Greenpeace or WWF, FoEI has sought to address environmental issues through a critique of social and political inequality, an explicit attack on neo-liberalism and a commitment to environmental justice as a central principle. ${ }^{4}$ Greenpeace has always framed its arguments in terms of a limited number of single-issue campaigns, avoiding broader ideological claims. WWF has in recent years oriented its work towards sustainable development as the best means to protect the natural world, but it remains cautious in comparison with FOEI about being perceived as radical, as its public image, traditions and sponsorship are closely tied with an establishment and non-political identity. For these reasons FoEI is the only one of the three largest transnational environmental NGOs where it is possible to see the negotiation of a common identity between environmental groups from Northern and Southern countries.

Added to these programmatic and organisational features, FoEI is also a significant case study because it has faced a recent crisis due to divisions over North-South questions between different national groups. Tensions emerged forcefully during and after the second UN World Summit on Sustainable Development (WSSD) in South Africa in 2002. The arguments within FoEI after the WSSD led to the resignation of Acción Ecológica (FoE Ecuador) who argued that Northern and Southern groups had contradictory ideological positions. This paper focuses on the process of renegotiating the nature of FoEI's identity that followed. It first describes the nature of the Federation then assesses the details of the arguments made by Acción Ecológica (AE) and others. This is followed by reflections on the collective culture that shapes how identity questions are articulated within the FoEI network.

The approach in this article to the question of how to assess the nature of FOEI's identity is based on Charles Tilly's (2002: 27) argument for methods based upon 'relational realism'. Tilly contrasts the stories told in social science with the standard stories that are used in everyday life to explain events. In standard stories there are a limited number of characters, a clear beginning and end in time, delimited space and the events of the story are a direct result of the deliberate actions of the characters. Stories of this kind are an inherent part of social life and help us to make sense of our relationships with others, but they are not social science. The role of social science is to tell particular kinds of stories which also take into account causes of action that are indirect, unintended, incremental or mediated by the non-human environment. The number of characters is not clearly 
limited, neither are there clear boundaries in space and time and not all events are a direct result of intended actions. For instance, in the field of social movements, networks based upon weak ties between groups not normally connected to each other will spread to mobilise more people than will action based in a network of strong ties between people who are very similar socially, although a strong ties network may sustain more demanding action for longer because of the interdependence of those involved (Granovetter 1973).

Tilly situates relational realism as an approach to social science explanation that lies between the isolated purposive actor of methodological individualism (whether based upon the rational actor or phenomenology) and the abstract and functionalist logic of structural explanations. This very general rubric is useful in the case of FoEI because it helps to categorise some of the bad explanations that emerged as competing stories within the network as it considered North-South questions in 2002-4. These stories were in effect variants on common social science explanations. For instance, some participants argued that structural differences in resources and political context between North and South explained the conflicts over strategy and identity. This was unconvincing because divisions over North-South issues did not map onto the structural positions of different national groups in FoEI. Others argued that exclusion of Southern groups from power occurred through deliberate and conscious choices, which reflected an analysis based on the purposive actor. There was also little evidence to support this kind of explanation in FoEI. To find an adequate explanation of how FoEI works we need to look beyond these two approached. Relational realism focuses on tracing mutual influences between actors as its core method. It seeks to add to the standard story of the purposive actor by bringing in a wider field of social relations, including unintended effects on action, indirect causes and the effects of the taken for granted assumptions bound up in the traditions and culture of groups. It does so, however, without excluding the effect of the incessant improvisation and dialogue that occurs in social relations. The centre of analysis is the process of interaction between participants in a social setting. This still leaves open a large area of difference in approach between those who take more structurally-influenced or more cultural approaches to explanation, but it rules out explanations based upon the causal effects of structures alone and alternatively those based wholly upon the purely self-propelling rational action of individuals. As I will argue, this is helpful in explaining how FoEI dealt with the unsettling challenge to its core identity after the WSSD. First, however, it is important to explain how FOEI works as an organization.

\section{Formal Structures}

Friends of the Earth International was founded in 1971 by four new FoE groups from France, Sweden, England and the USA. ${ }^{5}$ The intention was to mount joint campaigns on transnational issues such as nuclear 
energy and whaling. A small International Secretariat was established in 1981, initially staffed by volunteers, which rotated from country to country. By 1983 the organisation had grown to 25 members and an Executive Committee was elected to oversee the issues worked on between meetings. In 1986, the Annual General Meeting (AGM) was hosted for the first time by an organisation from the South, Sahabat Alam Malaysia (SAM/FoE Malaysia). At that time, FoEI had 31 members. As the network grew, its agenda shifted gradually to greater attention to the relationship between environment and development issues and in particular to the need to change lifestyle and consumption patterns in the North. The 1994 AGM decided that international cooperation should be further intensified through the development of an 'agenda' that presents common points of view within a coherent framework. In 2005 there were 71 Friends of the Earth member groups ${ }^{6}$ with a combined number of members and supporters of around 1.5 million, and the FoEI umbrella unites more than 5,000 local activist groups, with approximately 1,200 staff members (see Appendix). The Secretariat is permanently based in Amsterdam with a small multi-national professional staff.

FoEI is a federation based on the participation of autonomous national member groups. There is no requirement for members to adopt a particular form of organisation (though there has to be some internal democracy) or to have a minimum level of support before they can join. The national groups have to show that they are working to pursue FoEI's general mission and values and are expected to contribute to its international work, but if they disagree with an FoEI campaign they are also free to pursue their own position publicly, provided that they make it clear that this is not the position of the federation. FoEI member groups have to have a prior history of independent campaigning before they can join the network and have variable forms of organisation and membership structure. New members have to go through an assessment of their record by the FoEI Secretariat; by other national groups in their region; and by members of the executive committee. ${ }^{7}$ If successful they are then able to apply for a period of associate membership, which has to be approved by the whole network. After two years they are then eligible to apply for full membership rights. Membership applications can be controversial and acceptance is by no means automatic. And having got through this demanding process membership status is not necessarily secure since groups have been expelled for corruption, other infringements of rules, or for failure to maintain effective campaigning. Decisions of this consequence rest with the two yearly meeting of the whole network, the Biennial General Meeting (BGM), which also approves the campaigns, organisational rules and elects the 8-9 member Executive Committee (comprised of representatives from 8 national groups plus the Chair). Each national member group has one vote at the BGM, irrespective of the size of its membership or financial contribution to FoEI, which gives considerable formal power to some relatively small groups. Single-issue groups are not eligible to join the network, but they can become affiliates, which allows them to attend FOEI events, but does not give them voting rights. 
As the Appendix shows, the aggregate figures on membership and staff hide huge variety at the national level. Some groups such as FoE Philippines have no members, while Germany alone accounts for more than a fifth of the FoEI supporters or members. These differences reflect specific organisational histories and taken at face value they could be misleading as a guide to national strength. For instance, FoE Philippines is a group of environmental rights lawyers working in alliance with grassroots environmental groups. Although it is not a membership organisation it is part of a network with a wider activist base, although that base is not part of FoEI. FoE Germany/BUND is a federation of older regional conservation groups and newer local environmental and anti-nuclear groups formed in the 1970s with a relatively loose organisational structure. It plays an active role in FoEI, but is not necessarily a powerful group able to exert influence in proportion to the size of its membership. It may be less influential because it seems less committed than the Dutch or British branches to global environmental justice issues, perhaps because its membership has a tradition of engaging principally in local conservation work. ${ }^{8}$ Not all national groups are equally active within FoEI: they do not all attend the BGM (expenses for one representative per group are paid by FoEI) and around a quarter of groups, some from all regions, failed to pay their membership fees in 2003.

FoEI is still a small operation compared to Greenpeace International (GI). Where GI had an income of Eu $38.9 \mathrm{~m}$ in 2004 (Greenpeace 2005), FoEI's income in the same year was a mere 1.67m Euros (FoEI 2005). ${ }^{9}$ Of this, $16 \%$ came from fees (member groups pay $1 \%$ of their income to the Federation). Twenty groups had still failed to pay the fee due in April by September 2004. The largest source of income is from Foundations (such as Oxfam UK, NOVIB/Oxfam Neths, HIVOs, the Rausing Trust, the Ford Foundation) and government development agencies (such as the Dutch Foreign Ministry and the UK Department for International Development: FoEI 2003 and 2004). Three quarters of income goes to support specific projects of member groups, ${ }^{10}$ the remainder goes to the Federation itself, of which a third is to support the Executive Committee and the remainder to support the International Secretariat. As in many NGOs the fifteen staff of the IS feel short of funds and time and cannot always carry out all the tasks they are asked to. Similarly, the Executive Committee often fits its meetings around other FoEI events, and can work 16 hour days on these occasions.

\section{FOEI's Common Identity}

Given the small scale of FoEI's organisation compared to Greenpeace International and since member groups are first and foremost national groups focussed mainly on national level campaigns against governments and corporations in their own countries, it might reasonably be asked what is the FoEI network for, other than a means of distributing relatively small resources? FoEI claims substantive successes in a number of recent campaigns (FoEI 2003; 2004) and the network also takes collective pride in the successes of national FoE groups in their own campaigns. Transnational networks assist smaller and poorer groups 
with expertise, time and research in some cases (FoE France has recently helped FoE Cameroon monitor illegal logging, for instance) and many FoEI groups are also involved in other trans-national networks outside FoEI such as Oilwatch. In this sense there is clearly an instrumental dimension to the Federation, but a principal role of FoEI is to develop a common cross-national solidarity and common analysis of the structural causes of environmental destruction and possible solutions. The autonomy of national groups means that common perspectives and strategies cannot be taken for granted in the way that they are in Greenpeace and WWF. The idea that FoEI has created a common ideological bond between its member groups, notwithstanding the diversity of their histories and current political contexts, is its central defining myth. In this sense, despite its NGO structure, it has something in common with grassroots networks such as People's Global Action (see Routledge, this volume and Wood 2005).

FoEI sees itself as occupying a particular role in the international politics of the environment in developing an analysis, critique and common action on structural sources of ecological degradation and an explicit attack on neo-liberalism. It is hardly alone in that, but it is in a more radical position as a large environmental NGO than WWF or Greenpeace in its support for environmental justice as dependent upon resistance to neoliberal globalisation, a frame that has developed more clearly in the past decade alongside the growth of the global justice 'movement of movements' and which has been supported especially consistently by Southern branches of the network. A recent statement of FoEI's position on global justice makes this clear:

FoEI challenges the current export-oriented neoliberal economic development model as it is fundamentally flawed. It is based on a set of assumptions which do not reflect the reality of most people, do not incorporate requirements for environmental sustainability or social justice. Instead corporate globalisation has further impoverished people and increased the rate of environmental degradation. Forests are being clear-cut, minerals strip-mined and fossil fuels exploited at completely unsustainable rates to provide natural resources for the 'global economy'. Democracy is being eroded as power is concentrated in fewer and fewer hands. Biological and cultural diversity are dwindling at an alarming rate. Hard won social and environmental standards are threatened.

(FoEI Secretariat summary document for NOVIB, 2003)

As an analysis of global environmental politics FoEI puts forward a form of what Martinez-Alier (2002) has defined as the environmentalism of the poor, though given the apparent professional and educational qualifications of those who attend the network's meetings this perhaps could be more accurately defined as 
environmentalism on behalf of the poor (Bob 2001). FoEI documents and campaigns focus increasingly on justice, rights and resistance to oppression and exploitation. This has also meant increased discussion of alliances with other social movement groups. At the 2004 Croatia BGM Ricardo Navarro, the retiring Chair of FoEI, defined the organisation as a social movement as opposed to an NGO. Others commented that this would have been unthinkable in previous years. Alliances with other social movement groups might also be seen as necessary to the legitimacy of its claim to be an environmental justice group. FoE groups seek to support and work with autonomous grassroots campaigns. Consistent with this, in internal discussions, there is no sense of a competitive relationship with other transnational movement organisations. ${ }^{11}$ Instead, the emphasis is on developing effective alliances in which FoEI can play a constructive role.

Given our broad mission statement, FOEI almost always seeks to build alliances with other groups in civil society such as the development movement, indigenous peoples, farmers' movements, labour and academics. Two examples of such alliances are the joint work with Via Campesina for the trade campaign and our joint publications/campaigns with the World Rainforest Movement as part of our biodiversity/forest campaign.

Often the political priorities of non-environmental organisations correspond more closely to our agenda than the campaign priorities or strategies chosen by our environmental colleagues at WWF, Greenpeace or groups within the Climate Action Network. While we cooperate as much as possible with the latter, it is our task to push for issues of social justice within their more purely environmental agenda. (FOEI Secretariat summary document for NOVIB, 2003)

Given the weight given to environmental justice and rights from a global perspective in FoEI's official positions, how did the network become embroiled in arguments over justice and rights and North-South questions? To explain this requires an account of the departure of Acción Ecológica from FoEI in 2002.

\section{North-South arguments at the WSSD and Acción Ecológica}

One clear point of difference in the situation faced by FoEI member groups in the North and the South is that violence and repression is a widespread, albeit variable, threat to activists in many Southern groups. For example in 2005, an armed gang raided the office of FoE Colombia in Bogotá. This followed an earlier attack and death threats to activists and their families from a right-wing paramilitary group in 2002. In 2003 the FoEI General Meeting in Cartagena, Colombia was preceded by a conference on environmental rights attended by over three hundred campaigners. Alongside the speakers from the Brazilian landless workers' movement (MST), indigenous people's groups, and human rights NGOs, FoE activists from Nigeria and Honduras spoke about their own experience as victims of human rights abuses and political violence. 
This underlay the claim by Acción Ecológica (AE) that FoEI groups in the North had failed to understand how different the context was for groups in the South. AE argued that Northern groups were betting on reforms within a system that required resistance from outside. When AE resigned in the autumn of 2002 they argued that FoEI's participation in the WSSD had given priority to Northern agendas and been dominated by the representatives of Northern groups. Corporate accountability became the principal theme of FoEI's campaign, when AE saw corporations as beyond accountability and argued that seeking to encourage reforms and regulation simply reinforces existing structures. It was argued that too much of FoEI's work seemed to be driven by the search for positive media coverage and this resulted in too weakly expressed a rejection of the business agenda at WSSD of encouraging 'type 2' partnerships between corporations and civil society groups. AE also cited the failure of FoEI to formally support a march of unemployed South Africans protesting against neo-liberalism because of the fear that violence might develop. Southern branches of FoEI were weakened and their agendas 'invisibilized' by the Northern agenda, according to AE. Representatives of the FoE groups from South Africa, Nigeria and Uruguay supported many of these arguments.

The detail of what took place in Johannesburg was disputed in subsequent discussions. For instance, the decision not to participate in the Alexandra march was decided by the Executive Committee based on advice from the South African branch, but the detail was less important than the sense that the federation might divide on North-South lines. These were not wholly new arguments. The FoEI Executive Committee acknowledged that many of these issues had been simmering for some time. For instance, the 1999 AGM in Quito had been preceded by a three day meeting to consider North-South differences and a plenary debate had raised then many of the points that were made again in 2002 and 2003. Thus, the arguments about WSSD exposed a longer-standing feeling among some Southern groups that their priorities were not being recognised in the federation. Given the significance for FoEI of a common ideological bond based on global environmental justice, these criticisms went to the heart of its mission and purpose.

\section{Assessing the North-South Divisions in FOEI}

There were two main issues in this argument:

(1) Were there fundamental ideological and strategic differences between groups within the network?

(2) Was FoEI failing as an inclusive and democratic network? 
Although usually run together, these issues were, at least in theory, analytically distinct and some in FoE noted this. Meena Raman of SAM/FoE Malaysia (and later Chair of FoEI 2004-) argued that having a radical analysis of the causes of inequality and environmental injustice does not mean that the best strategies are necessarily radical. In the debates that followed AE's resignation there was an effort to define the network's ideological goals, while accommodating the differences in strategy that followed from different national histories. On the latter, some Southern groups stressed the centuries of looting of their national resources by colonial powers, and now by corporations, whether national or transnational, and aligned their struggles with those of indigenous peoples against a global model of development. However, Acción Ecológica seems to have been more radical in assessing the consequences of this for FoEI strategy than other Southern FoEI groups. For instance, AE questioned one of the main successes claimed by FoEI. The Extractive Industries Review by the World Bank had recommended pulling funding for oil and gas projects in developing countries. AE argued that this outcome was unsatisfactory because it did not challenge the legitimacy of external investment per se. Moreover, FoEI spoke only of achieving food security when it should emphasise food sovereignty. Another example was the use of the concept of ecological debt by AE to challenge the reformism of some Northern groups. European FoE groups had been proud of the development of the idea of ecological space (first put forward by FoE Netherlands at the Rio Earth Summit in 1992) but AE and some others saw this as too limited in its terms. Ecological space is the idea that each person has a per capita entitlement to the use of ecological resources within the limits necessary to achieve sustainability. This can be used to show the over-consumption of the North relative to the South and of Southern elites relative to a global model. What it excludes is the legacy of the effect of exploitation on the South. Thus ecological space is only acceptable to many if it is accompanied by an acknowledgement of ecological debt. This is based upon the principle that the wealthy of the North owe the South for the past benefits they have accrued though the use of ecological resources. Ecological debt is a redistributive principle, and difficult to quantify, but the debt is not wholly financial. It also involves redress for cultural and social injustice and thus also draws on principles of recognition. ${ }^{12}$

The idea of development is, as Escobar (1995) has argued, a western frame based on exporting the structures of western societies, which, over past fifty years has become so powerful that it is almost impossible to challenge. AE shared this post-colonial critique insofar as they argued that sustainability should not be based simply upon the North giving to the South, through methods such as technology transfer, since such models also increase dependence and fail to acknowledge that other indigenous modes of development and technology might be more appropriate. 
To what extent then were there fundamental ideological and strategic divisions on North-South lines within FoEI? Interestingly, in the debates after AE's departure there were multiple national stories and positions that did not fit into a clear North-South divide. FoE Australia supported many of the criticisms of the failure of the network to effectively include Southern agendas and groups, while some Southern groups, such as Malaysia, argued that some of the criticism of 'Northern' strategies was wrong. For instance, engagement with corporations to secure accountability was reasonable when it led to tighter controls on their activity or compensation for affected groups, although it should not extend to negotiation. Many groups sought also to disrupt the over-simplified use of 'North' and 'South' by acknowledging the 'South' within the North and vice versa, following the reasoning of the 'global North' and 'global South' in academic discourse. Some representatives of European groups felt that they were being misunderstood and misrepresented. They said that they had sought to expose the involvement of western corporations in injustices in other countries: FoE England Wales and Northern Ireland had produced a spoof shareholders report and demonstrations targeted at exposing Shell's involvement in environmental injustice globally. European groups had also begun to campaign on ecological debt (FoE Europe and FoE Scotland Ecological Debt Education Project) so it was not wholly accurate to define ecological debt as an exclusively Southern campaign theme. There were nevertheless still differences over how to approach campaigning on corporations. A representative of FoE Canada said in discussion at the BGM (Croatia, 2004) that they could not feasibly campaign in Canada for the abolition of the WTO and although they could imagine a world without corporations they did could not yet argue for one publicly. But, while there were certainly ideological and strategic differences within FoEI, these did not fit into a clear North-South pattern and nor were they fixed and permanent, with evidence that some groups in western Europe had changed their positions in response to arguments from some in the South.

The claim that decision-making is dominated by the Northern groups is central to the question of whether FoEI was failing to be inclusive, but the evidence on this is also not clear-cut. In 2002 The FoEI Chair was from El Salvador, and in the Executive Committee that took many of the controversial decisions, five out of its nine members were from Southern countries. ${ }^{13}$ It is also clear, however, that lack of resources affects the level of participation by Southern groups in FoEI activities. Many Northern groups were able to send several staff to the WSSD and so in the FoEI meetings they were over-represented and when consensus rather than voting was the mode of decision-making, they could have 'won' without any clear conflict appearing. The onus was on the smaller number of Southern representatives to be present at all such occasions and to reject consensus. A second more generic problem relates to language. The official languages of the network are Spanish, French and English. In practice, however, English is the lingua franca and FoEI (at best) tries to support the other two 
languages. The IS translates documents on its website into the other two languages, but its staff are over-worked and under-resourced and not everything is translated. AE argued that the move to greater use of the internet in internal debates was in fact discriminatory against the South, where connections were less reliable and this compounded the (English) language problem. The internet clearly aids the speed and range of distribution of documents, and has many advantages for international networks but it is not necessarily an egalitarian a method of communication. Language also affects the nature of faceto-face debates at meetings. Translation at BGMs is reliant on the efforts of volunteer staff with microphones and amplifiers, rather than headsets or translation booths. At the BGM in Croatia when a bye-law was proposed to move to full translation of all discussions and to employ translators, this was rejected as too costly, and not only by Northern groups. The unequal effects of lack of resources and language issues do not only affect groups from the South, but also limit the participation of groups from Eastern Europe, who do not even have the partial benefit of some translation into a language of everyday use. ${ }^{14}$ Fluent English speakers have a clear advantage in the structures of FOEI.

How far then was the critique of FOEI's failure as an inclusive network justified? There are inequalities of language and resources that limit equal participation within the network, but the other problem appears to be subtler. As representatives from the North (Italy) and the South (Uruguay) pointed out, there was a tendency to avoid confronting ideological differences and instead to celebrate the political diversity of the network. This meant that sometimes it presented a false image of unity based on platitudes. And while FoEI was willing to celebrate its radicalism, it also sought to avoid risks and thus constructed a common identity based on a low common denominator. REDES/FoE Uruguay felt that the principle of consensus, which is the norm in the federation's meetings, suppressed conflicts where open argument was needed. More will be said about this in the final section of the paper. For now, it is worth examining how the way FoEI dealt with this crisis also reproduced this general tendency to circumvent conflict.

\section{Resolving Difference and Managing Diversity}

In response to the tensions after the WSSD the FoEI Executive created a Network Process Team (a collection of eight representatives from local groups (two from each region - Asia Pacific, Africa, Latin American and the Caribbean, and Europe and North America) who volunteered to examine the question of how FoEI could manage its 'political diversity'. The regional structure of the NPT group was itself questioned, since representatives from countries could not necessarily represent whole regions, but once it became clear that its purpose was broadly deliberative - to seek to define the issues rather than to take decisions - it was less controversial. 
Six groups: Australia, Colombia, Costa Rica, France, Nigeria and Uruguay, then called for an Emergency General Meeting, to be held as part of the inter-BGM meeting already arranged for September 2003 in Cartagena, Colombia. An outside facilitator from India who specialised in work with NGOs was appointed and regional meetings were convened to deliberate on the NPT's core questions and consider how best to resolve them in Cartagena. Once this process began, there was a momentum towards reconciliation and resolution. Faced with the possibility that the network might collapse, it seemed that all preferred to step back from the brink. The NPT became more about rebuilding trust within FoEI than confronting and resolving major differences over ideology and strategy. The Cartagena EGM was designed using an open agenda which sought to encourage sharing perspectives rather than making policy, although it did produce a protocol clarifying how decisions were made at various levels within FoEI, and particularly at international gatherings. There was less unhappiness evidenced at FoEI's handling of its role at the 2003 WTO meeting in Cancun. ${ }^{15}$

As part of the reconciliation process, by the time of the next BGM in September 2004 in Croatia, there was a willingness to admit to mistakes. Northern groups accepted that they had worked too much within the terms of events such as WSSD. In turn, Ricardo Navarro, the retiring Chair from El Salvador, acknowledged the difficulties he had created for FoE USA when on a visit there in 2003 he said in an interview that the World Bank was responsible for more deaths than Saddam Hussein. A meeting on political diversity led by FoE Australia produced an interesting discussion on political differences, but in a consensual form, which in effect was an exchange of contexts and identities. Peace, was thus re-established within the network but a consequence of the North-South debate is that any claim about the identity or strategy shared by the Federation is now recognised as potentially difficult.

\section{Identities and Stories}

How should we think about the nature of FoEI's identity problems, as represented in this story? In the study of social movements, Melucci (1996) has been especially influential in emphasising the extent to which social movement identity is always partial, loose and has to be worked at constantly in response to internal debates and external events. This is certainly the case within FoEI, but there are also important points to be made that make this story more than a simple affirmation of the structural explanation of an inevitable North-South divide. It is clear that divisions over the issues raised in North-South divides do not map neatly into regional divisions between different member groups of FoEI. For instance, differences in political traditions between member groups can be crucial in crosscutting North-South divides, with both relatively conservative groups in the South (Chile) and radical groups in the North (Australia) and others such as those in Eastern Europe (neither clearly North nor South, and often more conservative than either most in Western Europe or the South) complicating 
dichotomous readings of the arguments. Furthermore, groups do not have fixed positions on these issues. Some European groups (notably the two UK groups) gave greatly increased emphasis to the importance of their ties with groups from the South in comparison with earlier years. They have sought common ground in searching for shared frames and made Southern perspectives more central in their campaigns (see Rootes, this volume). Until recently, Southern groups were critical of the significance attached to change climate issues by Northern branches of FoEI. Climate change had emerged as an issue through Western science and seemed to displace the current environmental injustices being experienced for a focus on a future problem. It was asked whether desertification and deforestation were so low in priority in comparison because their main effects were in the South. FoEI groups were able to agree to work together on climate change by placing its campaigns against oil, gas and coal industries within the framework of climate justice. This has meant making central the injustices faced by those most affected by the fossil fuel industries such as the victims of gas flaring in Nigeria, and the effects of extreme weather events on those with the fewest resources to protect themselves. A wholly structural explanation of North-South issues is unsatisfactory because of the diversity of positions on the strategic issues from national groups across a North-South divide and because there has been significant dialogue within FoEI. The willingness of Northern member groups to take risks with their domestic support by supporting global radical agendas and the lack of evidence of deliberate efforts by them to control the organisation also undermines accounts based upon national organisations acting as rational actors maximising their interests.

What is striking about the North-South argument in FoEI is the relative ease with which the network was able to manage the serious differences that emerged. Participatory processes of dialogue were central in this rebuilding of trust. Many of these depend on what Lichterman (1996) has defined it as 'personalism'. Personalism is a form of individualism found in many Western green and other social movement groups in which solidarity comes from individuals being open about their own failings and weaknesses with fellow activists and from working to achieve a consensus on which trust can rest. This seems to be a potential route into understanding some of the modes of participation in collective FoEI events, and, returning to Tilly, may be one of the examples of how its story is affected by taken for granted factors that are not necessarily part of the activists' own stories of the events. There are certainly many features of personalism evident in FoEI's culture, including decisions being taken by consensus whenever possible. Another example comes from the Cartagena Emergency GM, called to consider the crisis created by AE's decision to leave FoEI. This was organised according to the principles of 'Open Space technology'. ${ }^{16}$ Although this was an approach to meetings developed for management training (and its author claimed to be basing it on his observation in the 1960s of decisions made by a rural Ghanaian tribe, Owen 1997) it was based on principles familiar to anyone 
who has attended an Western green, women's liberation movement or other new social movement meeting in recent decades - an open agenda, much breaking into smaller groups and sending back spokespeople to the plenary to summarise discussion, and an orientation towards consensus (Polletta 2002). 'Open Space' was presented in some internal documents as providing an important new means to enable inclusive discussion and participation (FoEI 2004: 6). More revealing was the language used in the document that explained how 'Open Space' worked. Participants were assumed to be individuals, not representatives of groups. The following is an extract from an explanation of the Open Space method:

The one law is The Law of Two Feet, or in some cases, The Law of Personal Mobility. It says simply that you, and only you, know where you can learn and contribute the most to the work that must take place today. It demands that you use your two feet to go where you need to go and do what you need to do. If at any time today, you find that you are not learning or contributing, you have the right and the responsibility to move... find another breakout session, visit the food table, take a walk in the sunshine, make a phone call -- but DO NOT waste time. (FOEI Guide to Working in Open Space 2003)

Authenticity in confronting fears and coming to the discussion with 'passion', were said to be essential. The adoption of this format for the Cartagena meeting is an example of how personalist culture is taken for granted as universal in FoEI, but it is at least strange that a meeting of a federation of representatives of national groups should use a structure devised for individuals, who are assumed to have no differentiating commitments or responsibilities. And yet, in practice it made sense in terms of the traditions and practices that had developed within FoEI. As well as its formal structure, the federation can also be understood as a social network of a relatively small number of people. The BGMs and other collective meetings of the network are more than policy-making occasions. Aside from the meetings of the Executive Committee they are the only face-to-face occasions for the Federation. They last for a week or more and representatives who attend several such events can get to know the others well. It is significant that the divisive debates after 2002 were mostly in the form or emails and letters, and it was in the face-to-face meetings that trust was rebuilt. Thus, how these meetings take place is an important way of understanding FoEI's culture. Although personalism is seen by Lichterman as particular to some Northern social movement groups, it is not clear that its assumptions are necessarily exclusively Northern. ${ }^{17}$ For instance, the discussion on 'gender mainstreaming' in FoEI at the 2004 BGM began with a participatory exercise in which participants had to divide themselves into groups according to 'men, women or does not matter' and then explain their choice as individuals, reflecting the assumption that personal experience mattered. This and the workplan on gender mainstreaming in FoEI was organised by FoE Philippines. Personalist 
assumptions and even individualist organisational 'technologies' might therefore become a condition of working together for activists who may have quite different understandings of community and representativeness. As Polletta (2002) argues, the dichotomy between prefigurative (participatory) and strategic (hierarchical) decision making processes is misleading. Not only can participatory processes build the trust and solidarity necessary to joint action, they can also be developmental in training activists how to argue and how to listen. Since Polletta's study showed that participatory movements often split over what in retrospect seemed minor and often inter-personal differences (2002: 16), the ability of FoEI to maintain the network is a significant achievement in itself.

\section{Conclusion}

The arguments within FoEI seem to reveal much more of significance to understanding possible trajectories of transnational environmentalism in future decades. This is first because FoEI offers the most inclusive organisational structure in which Northern and Southern environmentalism interact and where groups have sought to re-examine their core principles. Although there may be an ideal type of Northern and Southern environmentalism, which is sometimes invoked by FoEI member groups, these positions do not map neatly onto national groups with variants of conservatism in the South and radicalism in the North and changes of position disrupting easy categories. There is no reason to see FoE national groups as necessarily representative of environmentalism in their own countries and in many cases, they clearly are not, but nor are Southern FoE groups satraps of a Northern controlled NGO. This is not contradicted by the arguments that came out of AE's departure from the network. There are inequalities of power within the network that affect its inclusiveness and unintended consequences of organising practices, such as the search for consensus, which may also reinforce inequality, but these do not prevent all effective debate. What the arguments within FoEI revealed were that FoEI has developed in Torgerson's terms (1999 and this volume) a trans-national green public sphere in which a number of terms such as environmental justice, and corporate power, remain contested and unstable: sources of solidarity and potential division. Nor is this likely to change. There is a sense in the discussions observed for this research that this is recognised as inevitable by most of the key participants in FoEI. It is important, however, that FoEI does not treat the next crisis over ideology or strategy as necessarily signalling the failure of its efforts to manage political diversity. If a solution is seen as essential it could lead to a new form of homogeneity. As Lichterman (1999: 104) argues, social movement forum spaces depend upon 'critically collective discussion about members' interests and collective identities' and 'the forum shrinks if members come to assume that their collective interests and identity are obvious and need not to be discussed, or if they talk only to strategize.' 
Appendix National Memberships and Staff, Friends of the Earth International 2002

\begin{tabular}{|c|c|c|c|c|}
\hline ntry & Member & staff & members & found \\
\hline GENTINA & Proteger/AdT Argentina & 1 & 70 & 84 \\
\hline STRALIA & FoE Australia & 2 & 4500 & 73 \\
\hline STRIA & Global 2000 & 30 & 60000 & 82 \\
\hline GIUM & AdT Belgium & 4 & 1200 & 76 \\
\hline VIN & AdT Benin & 0 & 950 & 88 \\
\hline LIVIA & centro de estudios regionales de tarija & & & 89 \\
\hline AZIL & Nucleo Amigos da Terra/FoE Brazil & 1 & 250 & 64 \\
\hline LGARIA & Ekoglasnost/FoE Bulgaria & 2 & 1000 & 89 \\
\hline MEROON & Centre for Environment and Development & 13 & 1200 & 94 \\
\hline NADA & FoE/Les Amis de la Terre Canada & 35 & 4000 & 78 \\
\hline ILE & CODEFF/FoE Chile & 28 & 4450 & 68 \\
\hline LOMBIA & CENSAT Agua Viva. & 11 & 9 & 89 \\
\hline STA RICA & COEICOCEIBA & 5 & 12 & 99 \\
\hline OATIA & Zelena Akcija-Green Action & 8 & 256 & 90 \\
\hline PRUS & FoE Cyprus & 1 & 340 & 80 \\
\hline ECH REPUBLIC & Hnut' Duha/FoE Czech Republic & 20 & 600 & 89 \\
\hline NMARK & NOAH/FoE Denmark & 1 & 1106 & 69 \\
\hline SALVADOR & CESTA & 65 & 3000 & 80 \\
\hline ГONIA & Eesti Roheline Liikumine/ FoE Estonia & 5 & 300 & 88 \\
\hline 「LAND & Suomen Maan YstŠvŠt ry/FoE Finland & $1 / / 2$ & 500 & 87 \\
\hline INCE & AdT France & 5 & 3000 & 70 \\
\hline ORGIA & Mtsvaneta Mozraoba/Dedamiwis Megobrebi/ & 9 & 5000 & 89 \\
\hline RMANY & Bund fur Umwelt und Naturschutz Deutschland & 30 & 350000 & 75 \\
\hline ANA & Friends of the Earth Ghana & 19 & 0 & 86 \\
\hline ENADA, WEST INDIES & FoE Grenada & 0 & 65 & 91 \\
\hline ITI & COHPEDA/AdT Haiti & 4 & & 93 \\
\hline NDURAS & Movimiento Madre Tierra & & & \\
\hline NGARY & Magyar Termeszetvedok Szovetsege / & 6 & 121 & 89 \\
\hline ONESIA & WALHI/FoE Indonesia & 23 & 50000 & 80 \\
\hline :LAND & Earthwatch/FoE Ireland & 3 & 1200 & 85 \\
\hline ،LY & Amici della Terra / FoE Italy & 12 & 25,300 & 77 \\
\hline 'AN & FoE Japan & 12 & 250 & 81 \\
\hline REA & Korean federation for environmental movement & & 80000 & 93 \\
\hline ГVIA & Vides aizsardzibas klubs/FoE Latvia & 3 & 3400 & 87 \\
\hline 'HUANIA & Lietuvos Zaliuju Judejimas & 4,2 & 600 & 88 \\
\hline XEMBOURG & Mouvement Ecologique/FoE Luxembourg & 3 & 3100 & 68 \\
\hline CEDONIA & Dvizenje na ekologistite na Makedonija/ & 7 & 10000 & 90 \\
\hline ،LAYSIA & Sahabat Alam Malaysia/FoE Malaysia & 7 & 100 & 77 \\
\hline ، LI & GUAMINA/FoE Mali & 43 & 66 & 88 \\
\hline LTA & Moviment ghall-Ambjent/FoE Malta & 0 & 320 & 85 \\
\hline URITIUS & MUDESCO/FoE Mauritius & 4 & 200 & 85 \\
\hline PAL & forum for protection of public interest & & & 91 \\
\hline THERLANDS & FoE Netherlands & 60 & 70000 & 72 \\
\hline TH ANTILLES & Amigu di Tera/FoE Cura $\leftarrow$ ao & 0,5 & 530 & 89 \\
\hline W ZEALAND & Friends of the Earth New Zealand & 0 & 370 & 75 \\
\hline ZARAGUA & centro humboldt & 42 & 300 & 90 \\
\hline
\end{tabular}




\begin{tabular}{|c|c|c|c|c|}
\hline JERIA & ERA/FoE Nigeria & 3 & 300 & 93 \\
\hline RWAY & Norges Naturvernforbund/FoE Norway & 15 & 25000 & 14 \\
\hline PUA NEW GUINEA & CELCOR & 10 & & 2000 \\
\hline RAGUAY & Sobrevivencia/AdT Paraguay & 23 & 101 & 86 \\
\hline रU & labor/AdT Peru & 10 & & 81 \\
\hline ILIPPINES & LRDC/FoE Philippines & 33 & 0 & 87 \\
\hline LAND & PKE/FoE poland & 5 & 4000 & 80 \\
\hline JTLAND (U.K.) & FoE Scotland & 15 & 5000 & 78 \\
\hline RRA LEONE & FoE Sierra Leone & 2 & 1000 & 89 \\
\hline JVAKIA & FoE Slovakia & 14 & 500 & 97 \\
\hline UTH AFRICA & GroundWork & 6 & & 99 \\
\hline IIN & AdT Spain & 6 & 15000 & 79 \\
\hline LANKA & Environmental Foundation Ltd./FoE Sri Lanka & 18 & 115 & 81 \\
\hline EDEN & Miljoforbundet Jordens Vanner/FoE Sweden & 3 & 2200 & 71 \\
\hline ITZERLAND & Pro Natura/FoE Switzerland & 44 & 98500 & 1909 \\
\hline GO & AdT Togo & 8 & 336 & 90 \\
\hline NISIA & ATPNE/ AdT Tunesia & 10 & 2000 & 71 \\
\hline .A. & FoE US & 40 & 20000 & 69 \\
\hline RAINE & Zelenyi Svit/FoE Ukraine & 3 & 10000 & 87 \\
\hline ITED KINGDOM & FoE EWNI & 137 & 100000 & 71 \\
\hline UGUAY & REDES/FoE Uruguay & 8 & 700 & 88 \\
\hline
\end{tabular}




\section{References}

Anheier, H. and Themudo, N. (2002) Organisational Forms of Global Civil Society: Implications of Going Global, in Glasius, M. Anheier, H. and Kaldor, M. (eds.) Global Civil Society 2002, Oxford: Oxford University Press, pp.191-216

Anheier, H. Glasius, M. and Kaldor, M. (2005) Global Civil Society 2004/ 5, London: Sage.

Bob, V. (2001)

Doyle, T. (2005) Environmental Movements in Majority and Minority Worlds, NJ, Rutgers University Press.

Edwards, M and Gaventa, J. eds (2001) Global Citizen Activism, London: Earthscan.

Escobar, A. (1995) Encountering Development: the Making and Unmaking of the Third World, Princeton, NJ: Princeton University Press.

Frank, D.J., Hironaka, A., and Schofer, E. (2000) 'The Nation-State and the Natural Environment over the 'Twentieth Century.' American Sociological Review 65 (1): 96-116.

Friends of the Earth International (2004) Annual Report 2003, Amsterdam. http://www.FOEI.org/about/index.html, accessed 31 October 2005.

Friends of the Earth International (2005) Annual Report 2004, Amsterdam. http://www.FOEI.org/about/index.html, accessed 29 September 2005.

Friends of the Earth Scotland (2003) Credit Where it's Due, The Ecological Debt Education Project, Edinburgh: Friends of the Earth Scotland.

Granovetter, M. (1973) 'The Strength of Weak Ties’ American Journal of Sociology, 68: 1360-80.

Greenpeace International (2005) Annual Report 2005, Amsterdam, http://www.greenpeace.org/international/press/reports, accessed 28 October 2005.

Johnson, E. and McCarthy, J.D. 'The Sequencing of Transnational and National Social Movement Mobilization: the Organisational Mobilization of the Global and US Environmental Movements', in della Porta, D. and Tarrow. S. (eds) Transnational Protest and Global Activism, Lanham, MD.: Rowman and Littlefield.

Kellow, A. (2000) Norms, Interests and Environmental NGOs: the Limits of Cosmopolitanism', Environmental Politics, 9, 3:1-22.

Lichterman, P. (1996) The Search for Political Community: American Activists Re-inventing Tradition, Cambridge: Cambridge University Press.

Lichterman, P. (1999) 'Talking Identities in the Public Sphere: Broad Visions and Small Spaces in Sexual Identity Poltics', Theory and Society, 28: 101-141. 
Martinez-Alier, J. (2002) The Environmentalism of the Poor, Cheltenham: Edward Elgar.

Melucci (1996) Challenging Codes: Collective Action in the Information Age, Cambridge: Cambridge University Press.

Owen, H. (1997) Open Space Technology: A User's Guide, second edition. San Francisco, CA: BerrettKoehler.

Polletta, F. (2002) Freedom is an Endless Meeting: Democracy in American Social Movements, Chicago: University of Chicago Press.

Princen, T. and Finger, M., eds (1994) Environmental NGOs in World Politics, London: Routledge.

Rootes, C. ed. (2004) 'Environmental Movement in Soule, S., Kriesi, H.P. and Snow, D.A (eds.) The Blackwell Companion to Social Movements, Oxford: Blackwell, pp.608-640.

Rupp, L. and Taylor, V. (1999) 'Forging Feminist Identity in an International Movement: A Collective Identity Approach to Twentieth-Century Feminism', Signs 24(2): 363-86.

Smith, J. (2002) 'Bridging Global Divides? Strategic Framing and Solidarity in Transnational Social Movement Organisations', International Sociology, 17, 4: 505-528.

Tarrow, S. and della Porta, D. "Conclusion: "Globalization," Complex Internationalism and Transnational Contention (2005) in della Porta, D. and Tarrow, S. (eds.) Transnational Protest and Global Activism, Lanham, MA: Rowman and Littlefield

Tilly, C. (2002) Stories, Identities and Political Change, Oxford: Rowman and Littlefield.

Torgerson, D. (1999) The Promise of Green Politics, Durham, NC: Duke University Press.

Wood, L.J. (2005) 'Bridging the Chasms: the Case of People's Global Action', in Bandy and Smith (eds.), pp.95-117.

\footnotetext{
${ }^{1}$ This paper is based on a project funded by the Economic and Social Research Council (RES-155-25-0008) and carried out by the author with Timothy Doyle. I am grateful for the comments provided by Timothy Doyle, Chris Rootes and an anonymous referee for Environmental Politics.

${ }^{2}$ For this paper we are drawing on data gathered at the FOEI biennial meeting in Croatia in September 2004 and documents provided by FoE Australia on their work in FOEI.

${ }^{3}$ In 2004 there were Greenpeace offices in 38 countries, 13 of which were outside the global North: Argentina, Brazil, Chile, China, Fiji, India, Mexico, Lebanon, Papua New Guinea, Philippines, Thailand, Tunisia and Turkey.

${ }^{4}$ For more detail on Greenpeace WWF and FOE in the UK, see Christopher Rootes' paper on the UK environmental movement, this volume.

${ }^{5}$ The brief history in this paragraph is based on one from the FOEI annual report (2004).

${ }^{6}$ There are 71 groups in 70 countries (two from Belgium) see table 1.

${ }^{7}$ Although FOEI began as a Northern federation, the need to demonstrate a prior history of effective independent campaigning before being considered for membership shows that it does not fit the argument of Frank et al (2000) that transnational mobilization of the environmental movement precedes national mobilization. Rather, the sequence of growth of 'chapters' of FOEI tends to support Johnson and McCarthy's (2005: 89) argument that a higher percentage of national environmental organisations in the South are likely to be members of transnational environmental networks than in the North because they have a greater incentive to seek the extra resources and legitimacy that membership brings.

${ }^{8}$ Norwegian FoE is in a similar position.
} 


\footnotetext{
${ }^{9}$ This is also a consequence of the greater centralization of resources in Greenpeace. Worldwide Greenpeace had an overall income of $158.5 \mathrm{~m}$ Euro in 2004, with around a quarter of income being passed to the International Office. In contrast, FoE England Wales and Northern Ireland alone had an income of UK£5.48m for its political and campaigning arm and UK£3.1m for its educational charity in the year to April 2004.

${ }^{10}$ National groups have to apply for support for specific activities: in 2004 FOEI distributed 800,000 Euros to 38 of its member groups. Most support goes to Latin America, followed by Asia then Africa and then Europe. REDES/FOE Uruguay gets significant support because it is the base for activity that is significant for the whole network, such as an internet radio station 'RadioMundoreal' and a children's environmental network.

${ }^{11}$ Various groups noted at the 2004 BGM in Croatia that they were not engaged themselves in campaigning on some of FOEI's core thematic areas nationally as there were other groups in their countries with better expertise in those fields. Eg Philippines on GMOs and Canada on mining. The 2003 annual report acknowledges financial support from IUCN, WWF and Greenpeace among others.

${ }^{12}$ On ecological debt see: ENRED (the European Network for the recognition of the Ecological Debt); http:// www.enredeurope.org/principal.htm and Ecological debt campaign (Ecuador) http://www.deudaecologica.org/

${ }^{13}$ In 2002-4 The countries represented on the Ex-Com were Australia, Colombia, El Salvador, Indonesia, Paraguay, Sri Lanka, Sweden Switzerland and the UK.

${ }^{14}$ Although this does not entail sympathy for those who argue for more resources to be devoted to translation. The representative of one Eastern European group suggested that if all groups sent only fluent English speakers to the BGM the network could save money.

1540 campaigners from FOEI groups and the Secretariat were at Cancun for the WTO meeting.

${ }^{16}$ This should not be confused with the use of Open Space as a principle at the World Social Forums.

${ }^{17}$ Although the criticism of consensus decision-making as 'Northern' in PGA (Wood 2005: 108) and the debatable criticism of it as 'white' by black power groups in the USA in the late 1960s (Polletta 2002) might suggest as much.
} 